\title{
Avaliação do uso de lama fina de aciaria como aditivo na fabricação de concreto
}

\author{
Gilson de Souza Santos ${ }^{1 *}$ \\ Aline Pereira Leite Nunes ${ }^{2}$ \\ Wanyr Romero Ferreira ${ }^{2}$
}

\section{Resumo}

Comumente é perceptível a evolução das indústrias no tocante à eficiência produtiva, porém, não se percebe com a mesma robustez, soluções aos resíduos. Visualiza-se na construção civil diversas aplicações de resíduos industriais, entretanto, o resíduo sólido utilizado neste estudo não tem ainda aplicação em destaque. Trata-se da lama fina de aciaria, considerada como classe II-A, não inerte e não perigosa, o que implica em condições especiais de descarte em aterros, de acordo com a norma NBR 10004:2004. O estudo pretendeu avaliar as propriedades de resistência do concreto aditivado com o resíduo em diversos níveis, além de realizar suas caracterizações. O resíduo foi submetido a diversas análises, dentre elas, à qualitativa de propriedades físicas e granulométrica. Posteriormente, foi adicionado ao concreto e os corpos de prova submetidos a ensaio de resistência à compressão axial simples. Os testes mostraram resultados superiores ao concreto convencional. Em relação ao corpo de prova sem adição de lama fina de aciaria, o corpo de prova com adição de 5\% da lama apresentou um ganho de 37,31\% na resistência à compressão axial na idade de 28 dias. Portanto, o estudo aponta às siderúrgicas uma aplicação valiosa do resíduo e reforça a importância de estudos e aplicação das ciências na busca de soluções.

Palavras-chave: Resíduos; Sustentabilidade; Lama de aciaria; Concreto.

\section{Evaluation of the fine steel sludge as additive in concrete manufacturing}

\begin{abstract}
The evolution of industrial processes is usually noticeable in terms of productive efficiency, but it is not perceived with the same robustness the direction of resources for solutions to the residue generated. It is noticed various industrial residue applications on construction industry, however, the solid residue used in this research does not yet have a highlighted application. It is a steel slag, considered as class II-A, not inert and non-hazardous, which implies special conditions of disposal, in accordance with the NBR 10004: 2004 standard. The aim of the study was to evaluate the strength properties of the additive concrete with different levels of residue, besides performing its characterizations. The residue was submitted to several analyzes, among them the qualitative of physical and granulometric properties. Subsequently, it was added to the concrete and the specimens submitted to simple axial compressive strength test. The tests showed better results than conventional concrete. Compared to the specimen without the steel slag addition, the specimen with the addition of 5\% sludge showed a $37.31 \%$ gain in axial compressive strength at the age of 28 days. The study, therefore, points out to steel companies a valuable application for the slag, emphasizing the importance of sciences application in the search for solutions.
\end{abstract}

Keywords: Waste; Sustainability; Steelworks slag; Concrete.

\section{Introdução}

Os processos produtivos na siderurgia geram volumes elevados de resíduos. De acordo com estimativas do Instituto Aço Brasil, cerca de $450 \mathrm{~kg}$ de "coprodutos e resíduos" são originados a cada tonelada de aço produzido.
Este valor está relacionado à rota tecnológica empregada e já chegou a superar a marca de $700 \mathrm{~kg}$. Deste montante, $80 \%$ em média são reciclados ou reutilizados seja no ciclo do aço ou em outros processos [1]. No Brasil são geradas

${ }^{1}$ Faculdade Pitágoras, Ipatinga, MG, Brasil.

${ }^{2}$ Faculdade IETEC, Belo Horizonte, MG, Brasil.

*Autor correspondente: gilsonss14@hotmail.com

2176-1523 (C) 2020. Santos et al. Publicado pela ABM. Este é um artigo publicado em acesso aberto (Open Access) sob a licença Creative Commons Attribution, que permite uso, distribuição e reprodução em qualquer meio, sem restrições desde que o trabalho original seja corretamente citado. 
anualmente 230 mil toneladas de lamas de aciaria LD (LinzDonawitz), que poderiam ser reutilizadas no próprio processo produtivo do aço. No entanto, a umidade desse resíduo é normalmente elevada, sendo da ordem de $15 \%$ na fração grossa, e de $30 \%$ na fração fina, constituindo um problema a sua reutilização em decorrência dos custos associados à secagem $[2,3]$. A presença de contaminantes, em particular o zinco, também é um fator limitante para a reutilização no processo produtivo do aço, portanto, é imprescindível remover o zinco da lama de aciaria LD anteriormente à sua reutilização no processo [4].

Uma solução ambiental e econômica para diminuir os impactos causados pelos resíduos gerados na aciaria é a aplicação destes como matéria-prima em outras indústrias, entre as quais a construção civil, que tem um grande potencial de utilização, já que ela chega a consumir até $75 \%$ de recursos naturais [5-7]. Segundo Santos e Borja [8], dentro da construção civil é possível ver algumas formas de reciclagem de resíduos industriais que se consolidaram como materiais para aplicações específicas. O setor siderúrgico brasileiro, atualmente posicionado como $9^{\circ}$ maior produtor mundial, foi responsável em 2014 pela produção de 33,9 milhões de toneladas de aço bruto, mas responde também pelo montante de 22 milhões de toneladas de "coprodutos" gerados no mesmo ano [1]. Neste cenário, alternativas de tratamento, como a reutilização e a reciclagem, apresentam-se como uma solução duplamente benéfica, pois contribuem não apenas evitando que este volume de resíduos seja simplesmente disposto em aterros, mas com a minimização do uso de recursos naturais não renováveis [9]. O Instituto Aço Brasil, responsável por criar o centro de coprodutos Aço Brasil, aponta a possibilidade de uso de agregados siderúrgicos na fabricação de cimentos, pavimentação de vias, dentre outras aplicações [1]. Com a produção em alta escala, torna-se inevitável e assustadora a geração de resíduos em todo o planeta. A degradação ambiental, o risco do colapso ecológico, a globalização e o avanço da desigualdade e da pobreza são reflexos da crise do mundo globalizado [10].

As lamas de aciaria, que representam cerca de 5\% dos resíduos, provêm do tratamento dos gases por via úmida e são formadas por óxidos de ferro, cálcio, silício, manganês e alumínio $[1,11,12]$. A lama fina de aciaria é classificada de acordo com a norma NBR 10004:2004 como resíduo classe II-A, o que exige condições especiais de descarte. Para cada tonelada de aço bruto produzido são recolhidos, em média, de 15 a $25 \mathrm{~kg}$ de lama fina de aciaria LD. Na unidade industrial da Aperam South América, na cidade de João Monlevade, por exemplo, considerando-se os anos compreendidos entre 2007 a 2010, a geração específica de lama variou de 5,6 a $7,2 \mathrm{~kg} / \mathrm{t}$ de aço bruto para a lama grossa, e de 17,0 a $22,8 \mathrm{~kg} / \mathrm{t}$ de aço bruto para a lama fina $[4,13]$.

A lama de aciaria é um resíduo que exige atenção dentro das siderúrgicas devido as suas características agressivas ao meio ambiente. Há poucos estudos sobre sua aplicação sendo que apenas $1,09 \%$ visam sua reutilização e reciclagem. Em contrapartida, a escória é o resíduo sólido de maior interesse entre os pesquisadores, com quase $81 \%$ dos trabalhos com ênfase nas suas aplicações [13].

A reciclagem de lama de aciaria gerada nas siderúrgicas de aço tem se tornado um desafio para diversos países. Atualmente alguns processos incluem a desidratação e aglomeração do resíduo, pois a desidratação seguida de aglomeração é o passo essencial para a utilização da lama de aciaria, segundo Singh et al. [14]. Na Alemanha, a Thyssen Stahl AG, Duisburg, iniciou o esforço de reciclagem da lama de LD através de testes laboratoriais e de plantas piloto no final dos anos 80. Aproximadamente 1600 toneladas de briquetes foram produzidos na planta piloto e foram carregadas em convertedor LD. Uma planta comercial foi construída para uso contínuo devido às respostas satisfatórias [14].

A utilização de subprodutos industriais em concreto tem recebido mais atenção dos pesquisadores, uma vez que contribuem significativamente para melhorar as propriedades do concreto de cimento e também reduz os problemas ambientais. A inclusão de ampla gama de sólidos, tais como restos de aço, escória e óleo de palma como substituto de materiais no concreto de cimento, além de melhorar a durabilidade, promovem a limpeza ambiental e eliminação maciça de resíduos [15].

No entanto, existe ainda na literatura enorme escassez de estudos sobre estes materiais como substitutos do cimento em concreto e não existem trabalhos intensivos, sobre as possibilidades de utilização de resíduos em produções de concreto, exceto na produção de cerâmica [16]. Considerando a gravidade da situação ambiental, o estudo tem como objetivo avaliar as propriedades de resistência do concreto aditivado com lama fina de aciaria, assim como os benefícios econômicos da aplicação da lama na fabricação do concreto.

\section{Materiais e métodos}

\subsection{Materiais}

Para o estudo foi utilizado cimento Portland Cauê CP III RS 40. O agregado graúdo - brita de origem artificial, de tamanho 3/8' (9,53 $\mathrm{mm}$ ) e o agregado miúdo - areias constituídas principalmente por quartzo, foram ambos extraídos na região do Vale do Aço. Foram utilizadas amostras de lama fina de aciaria provenientes da siderurgia instalada na região do Vale do Aço, MG, denominada como Empresa "A", com capacidade de produção de 9,5 milhões de toneladas de aço bruto por ano, a qual atende os mercados nacional e internacional.

\subsection{Métodos}

Os ensaios de caracterização dos agregados e da lama fina de aciaria, além dos ensaios de resistência do concreto, foram desenvolvidos nos laboratórios da empresa geradora "A" e nos laboratórios da Faculdade Pitágoras de Itabira. 


\subsubsection{Caracterização dos agregados}

A determinação da granulometria dos agregados foi realizada obedecendo aos requisitos estabelecidos na norma NBR NM 248 'Agregados: Determinação da composição granulométrica'. A determinação da massa específica dos agregados foi realizada obedecendo aos requisitos estabelecidos nas normas NBR NM 53 e NBR NM 52.

\subsubsection{Caracterização da lama fina de aciaria}

Para o estudo, amostras foram retiradas diretamente dos filtros do tambor rotativo da aciaria e colocadas em recipiente adequado, obedecendo a preconização definida na norma ABNT NBR 10007. Uma massa de $60 \mathrm{~kg}$ de lama fina de aciaria foi obtida neste processo.

A amostra passou pelos processos de secagem, homogeneização e amostragem, sendo obtidas diversas alíquotas para caracterização física e química e para os ensaios de resistência.

Foram realizados os ensaios de distribuição granulométrica em 7 alíquotas da lama fina de aciaria, utilizando-se um sistema de peneiras, marca Solotest, variando-se a abertura das malhas das peneiras entre $589 \mu \mathrm{m}$ e $38 \mu \mathrm{m}$ e um difratômetro a laser (Malvern, modelo Mastersizer 2000). A composição mineralógica das diferentes frações granulométricas da lama fina de aciaria foi determinada por meio de difração de raios-X. O equipamento utilizado foi da marca Rigaku, modelo Geigerflex, com radiação incidente "Anodo de cobre" ( $\lambda=1,54056 \dot{A})$, aceleração com tensão de $40 \mathrm{kv}$ e corrente de $40 \mathrm{~mA}$, intervalo de 4 a $70^{\circ}(2$ theta) e passo de 0,02grau/segundo.

Para caracterização química, com exceção do carbono e enxofre, utilizou-se espectrômetro de fluorescência de raios-X. O equipamento utilizado foi da marca Siemens, modelo SRS3000. A análise realizada foi semiquantitativa, em que a curva de calibração utilizada foi baseada em amostras contendo vários elementos da tabela periódica em diferentes concentrações, fornecida com o equipamento. Os resultados foram reportados na forma de seus óxidos. A análise do teor de carbono foi feita no equipamento LECO, modelo RC 412. A determinação do teor de enxofre também foi feita no equipamento LECO, modelo SC-432 DR.

Foram selecionadas algumas amostras da lama fina de aciaria para verificação por outras técnicas analíticas de análise química e foram reavaliados os parâmetros zinco, ferro total, ferro metálico e óxido de ferro $(\mathrm{FeO})$, cálcio, magnésio, silício, fósforo, sódio, potássio e chumbo. Para a reavaliação das análises químicas de zinco, cálcio, magnésio, silício, fósforo, sódio, potássio e chumbo, foram selecionadas, aleatoriamente, doze amostras e utilizada a técnica por espectrometria de emissão óptica com plasma induzido, equipamento Spectro, modelo Espectroflame Modula. Inicialmente, as análises de ferro total, ferro metálico e óxido de ferro foram feitas por titulação colorimétrica com dicromato de potássio, conforme procedimento da empresa geradora da lama fina de aciaria.

Em função das dificuldades encontradas, análises quantitativas por espectroscopia Mössbauer por transmissão foram realizadas para a especiação do ferro. As análises foram executadas no Laboratório de Espectroscopia Hiperfina e Física de Superfícies, do Departamento de Física, da Universidade Federal de Minas Gerais. Para tal, foi utilizada uma fonte de $57 \mathrm{Co}$, isótopo este que decai para o estado excitado de $57 \mathrm{Fe}$ radioativo. $\mathrm{O}$ ensaio foi feito sob temperatura ambiente, cujo tempo mínimo gasto para cada amostra foi de 72 horas, com velocidade máxima de $11,5 \mathrm{~mm} / \mathrm{s}$. A detecção de radiação foi realizada através de um contador proporcional a gás.

\subsubsection{Preparação do concreto e ensaios de resistência}

Para a produção do concreto os componentes foram medidos de acordo com os requerimentos da NBR 12655 'Concreto de cimento Portland: Preparo, controle e recebimento', e misturados até formar uma massa homogênea. Esta operação foi executada em laboratório através de equipamento de mecânico (betoneira) atendendo às especificações do fabricante quanto à capacidade de carga, velocidade e tempo de mistura. $\mathrm{O}$ traço do concreto foi definido em dosagem experimental conforme os pré-requisitos estabelecidos na NBR 12655 'Concreto: Preparo, controle e recebimento'. A moldagem dos corpos de prova obedeceu aos requisitos da norma NBR 12821 'Preparação de concreto em laboratório: Procedimento' e NBR 5738 'Concreto: procedimento para moldagem e cura de corpos de prova'.

Foram fabricados 16 corpos de prova, sendo que em 12 corpos de prova foram adicionados três percentuais diferentes de lama fina de aciaria, sendo eles referentes à quantidade do agregado miúdo (areia) no concreto (Tabela 1). Portanto, os ensaios foram realizados em triplicata, sendo os resultados a média aritmética das medidas observadas.

Após a moldagem, os moldes foram colocados em superfície horizontal, rígida, livre de vibrações e interferências externas de qualquer meio que provocasse perturbação no concreto. Durante as primeiras 24 horas todos os 16 corpos de prova foram armazenados em local protegido e livre de intempéries. Após, os corpos de prova foram armazenados em tanque de cura, dos quais 04 corpos de prova permaneceram durante 07 dias, 04 permaneceram durante 14 dias e 08 permaneceram durante 28 dias.

Tabela 1. Composição dos traços de concreto com adição da lama fina de aciaria

\begin{tabular}{clccc}
\hline \multirow{2}{*}{ Material } & \multicolumn{4}{c}{ Níveis aditivados em percentual } \\
\cline { 2 - 5 } & $\mathbf{0 \%}$ & $\mathbf{5 \%}$ & $\mathbf{1 0 \%}$ & $\mathbf{2 0 \%}$ \\
\hline Cimento $(\mathrm{kg})$ & 4,60 & 4,60 & 4,60 & 4,60 \\
Areia $(\mathrm{kg})$ & 6,76 & 6,76 & 6,76 & 6,76 \\
Brita $(\mathrm{kg})$ & 7,22 & 7,22 & 7,22 & 7,22 \\
Água $(\mathrm{kg})$ & 1,65 & 1,65 & 1,65 & 1,65 \\
Lama $(\mathrm{kg})$ & 0,00 & 0,34 & 0,68 & 1,35 \\
\hline
\end{tabular}


O ensaio de resistência à compressão axial do concreto obedeceu aos requisitos estabelecidos na norma NBR 5739 'Concreto: Ensaio de compressão de corpos de prova cilíndricos’.

\section{Resultados e discussão}

\subsection{Agregados}

O agregado graúdo brita apresentou massa específica aparente de $1,39 \mathrm{~g} / \mathrm{cm}^{3}$, próximo do valor apresentado pela areia, cujo valor foi de $1,29 \mathrm{~g} / \mathrm{cm}^{3}$. Ele também possui pouca porosidade, favorável para a produção de concreto. $\mathrm{O}$ agregado miúdo, caracteriza-se como areia natural, com tamanho máximo de partícula de 2,36mm e módulo de finura igual a 3,3. A granulometria dos agregados apresentou resultados dentro do recomendado na NBR NM 248. Na Figura 1, é possível comparar a similaridade nos resultados de granulometria da areia e da lama fina de aciaria.

\subsection{Caracterização física e química da lama fina de aciaria}

$\mathrm{Na}$ análise granulométrica por peneiramento, as partículas da lama fina de aciaria apresentaram granulometria $85 \%$ passante em $38 \mu \mathrm{m}$. Essa fração, por corresponder a um elevado percentual da amostra, foi submetida à análise de tamanho de partículas por difração a laser. Verificou-se que, em média, $70 \%$ das partículas estão abaixo de $10 \mu \mathrm{m}$,

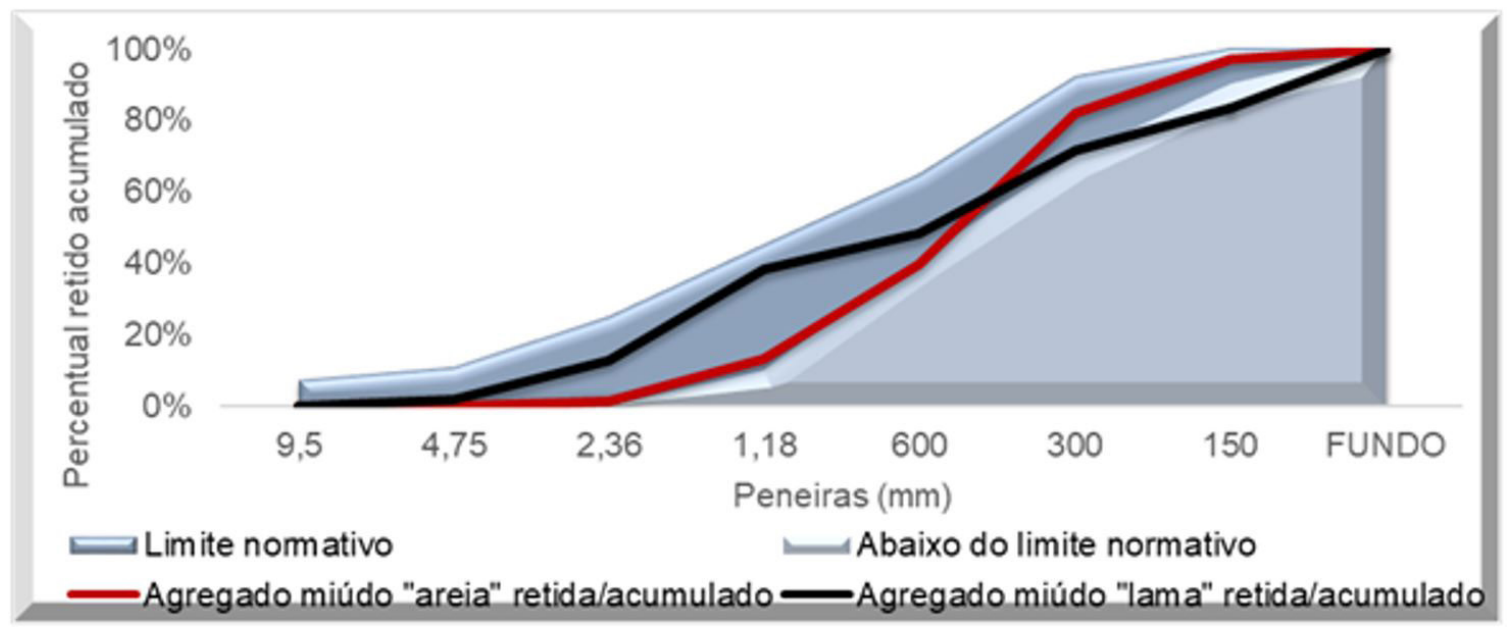

Figura 1. Granulometria do agregado miúdo.

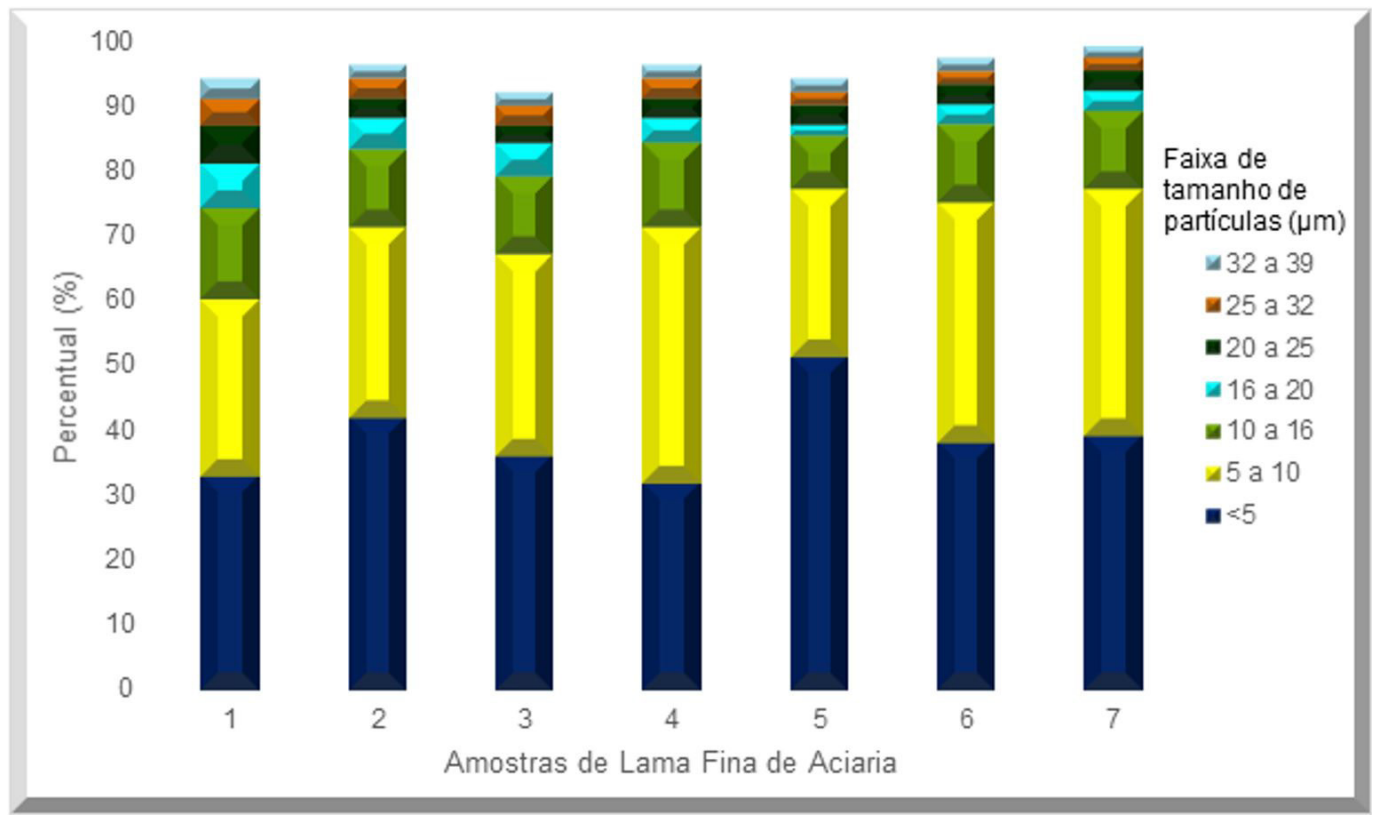

Figura 2. Distribuição granulométrica da Lama Fina de Aciaria, avaliada por difração a laser. Média do peneiramento a úmido (\%) para um Intervalo de confiança de 95\%: 85,5714 $\pm 5,4064$; ou [80,168,90,9778]. Média da difração a laser (\%) para um Intervalo de confiança de 95\%: $66,8226 \pm 8,8226$; ou $[58,006,75,6512]$ 
conforme ilustra a Figura 2. Verificou-se, ainda, que 66\% das partículas apresentaram-se abaixo de $38 \mu \mathrm{m}$.

Comparando os resultados de percentuais de partículas abaixo de $38 \mu \mathrm{m}$ dos dois métodos verificou-se que, ao nível de significância de $95 \%$, os resultados são consideravelmente diferentes. Os resultados da análise estatística podem ser observados na Figura 3.

Uma explicação para a diferença encontrada entre os resultados está associada aos princípios de funcionamento em cada ensaio. $\mathrm{O}$ ensaio de distribuição granulométrica por peneiras determina o percentual de tamanho de partícula com base na massa recolhida do material nas peneiras. Assim, materiais com elevada densidade devem influenciar os resultados, fato que não ocorre com o método de difração a laser, que se baseia no princípio óptico para determinação do tamanho de partículas. Como a lama fina de aciaria apresenta quantidade substancial de ferro, esta hipótese deve ser levada em consideração. Além disso, outros fatores, tais como: propriedades superficiais da partícula, abertura da peneira e carga da partícula, podem afetar a eficiência do peneiramento. Através da análise por difração de raios X, obteve-se as fases da lama fina de aciaria conforme descrito na Tabela 2.

Os elementos que apresentaram concentração mais significativa através das análises semiquantitativas por fluorescência de raios $\mathrm{X}$, na forma de seus óxidos, foram o cálcio, o magnésio, o zinco, e o silício. $\mathrm{O}$ manganês, o potássio, o alumínio, o fósforo, e o enxofre, diferenciaram pouco de uma fração da lama para outra e também apresentam concentração baixa, quando comparados aos outros elementos presentes. $\mathrm{O}$ fósforo e o alumínio apresentam uma concentração média maior na lama grossa comparada à fração fina. Já potássio, enxofre e manganês apresentaram concentração média maior na fração fina. Os resultados das análises químicas de carbono e enxofre (LECO) nas amostras da lama fina de aciaria foram muito baixos, sendo $1,2 \% \mathrm{e}$ $0,07 \%$, respectivamente.
Como não foi possível realizar análise da especiação do ferro para todas as amostras, apenas os resultados correspondentes ao ferro total são apresentados por diferentes análises. Na Figura 4 é apresentado o resultado da análise química de ferro total por titulação colorimétrica.

Os resultados das espécies de ferro, utilizando a técnica por espectrometria Mössbauer, mostraram a presença

Tabela 2. Fases da lama fina de aciaria

\begin{tabular}{|c|c|c|}
\hline \multirow{2}{*}{$\begin{array}{c}\text { Cartão de } \\
\text { Identificação } \\
\text { ICDD-PDF2 }\end{array}$} & \multicolumn{2}{|c|}{ Fases da Lama Fina } \\
\hline & $\begin{array}{l}\text { Fórmula } \\
\text { Química }\end{array}$ & Definição \\
\hline 6-0696 & $\mathrm{Fe}$ & Ferro, (WL: 1,5406Ao) \\
\hline $6-0615$ & $\mathrm{FeO}$ & $\begin{array}{l}\text { Óxido de Ferro, } \\
\text { (WL: } 1,5406 \mathrm{Ao} \text { ) }\end{array}$ \\
\hline $26-1076$ & $\mathrm{C}$ & Carbono, (WL: 1,5406Ao) \\
\hline $5-0586$ & $\mathrm{CaCO}_{3}$ & $\begin{array}{l}\text { Carbonato de Cálcio, } \\
\text { (WL: 1,5406Ao) }\end{array}$ \\
\hline $11-0614$ & $\mathrm{Fe}_{3} \mathrm{O}_{4}$ & Magnetita, (WL: 1,5406Ao) \\
\hline 24-0217 & $\mathrm{Ca}_{3} \mathrm{Al}_{2}(\mathrm{OH})_{12}$ & Catoita, (WL: 1,5406Ao) \\
\hline
\end{tabular}

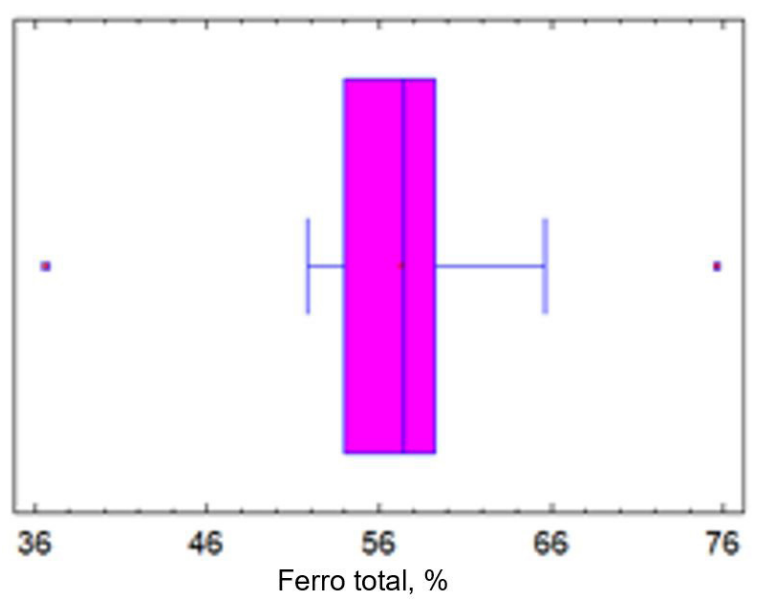

Figura 4. Resultado da análise química de ferro total por titulação colorimétrica da amostra da lama fina de aciaria.

\section{Método 1: Peneiramento a Úmido}

Método 2: Difração a Laser

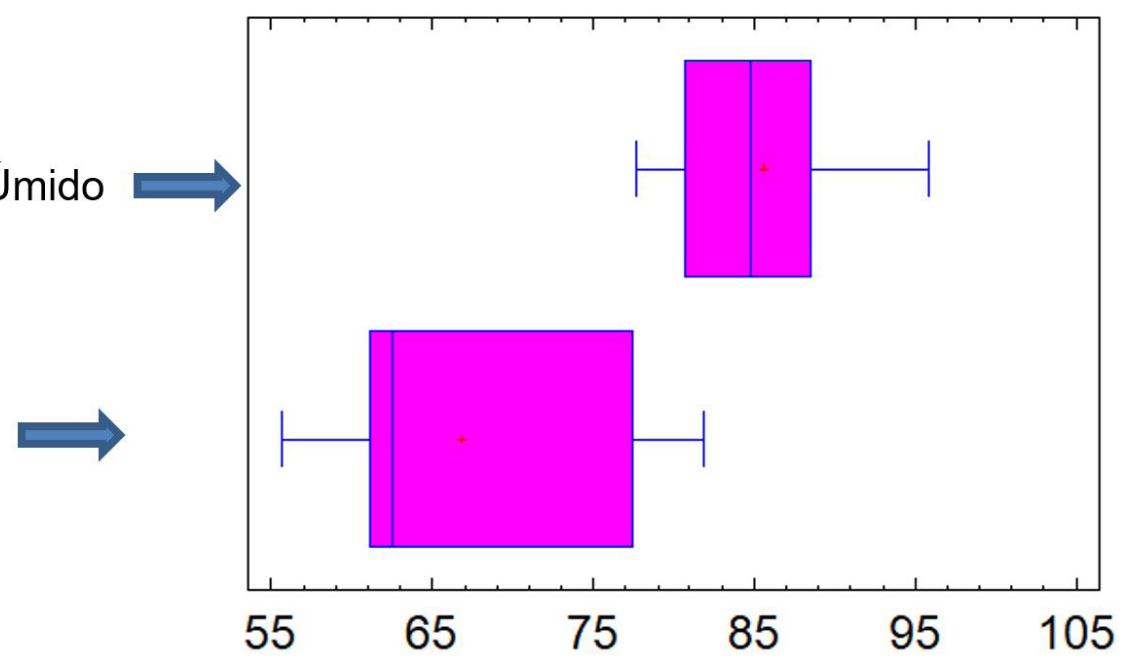

Figura 3. Análise estatística de comparação de médias dos percentuais de partículas abaixo de $38 \mu \mathrm{m}$ para lama fina de aciaria (abaixo de $38 \mu \mathrm{m}$ ). 
de ferro metálico $(\mathrm{Fe}-\alpha)$, magnetita $\left(\mathrm{Fe}_{3} \mathrm{O}_{4}\right)$ e wustita $(\mathrm{FeO})$ como constituintes principais da lama de aciaria. A Figura 5 mostra o espectro de uma amostra de lama fina de aciaria. Óxidos de ferro nanoparticulados apresentaram o fenômeno de superparamagnetismo, causando uma linha central alargada (singleto) nos espectros. Não foi possível precisar a natureza exata do(s) óxido(s) neste caso. No entanto, é provável que represente uma mistura de óxidos.

Baseado nas fases identificadas e considerando a presença de óxidos, foi calculada a composição química da lama fina de aciaria, conforme observado na Figura 6. Resumidamente, a lama de fina de aciaria é composta principalmente por ferro e cálcio, representando cerca de $65 \%$. Na mesma figura também e possível visualizar que o

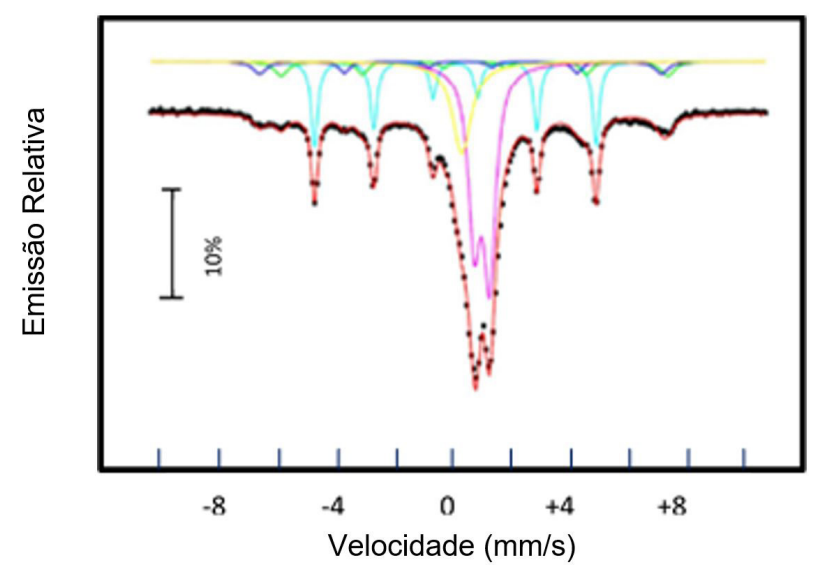

Figura 5. Espectro de Mössbauer da lama fina de aciaria.

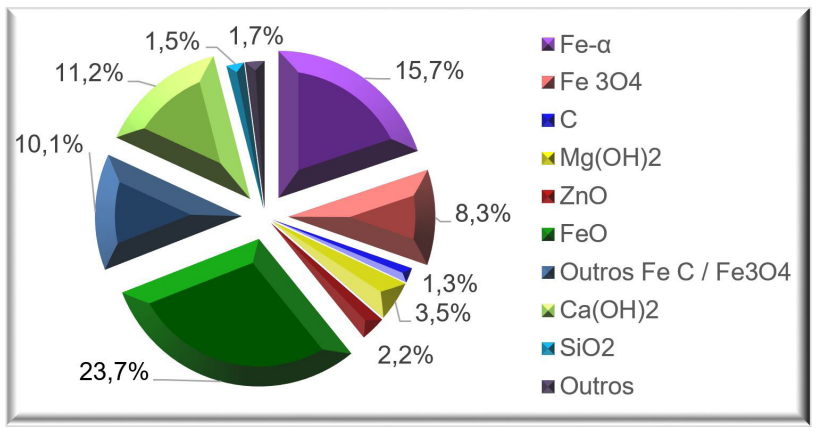

Figura 6. Composição química da lama fina de aciaria. magnésio, silício, zinco e carbono estão presentes na lama fina de aciaria atingindo concentrações abaixo de $2 \%$.

$\mathrm{O}$ zinco, particularmente, apresenta-se na lama fina de aciaria em concentração média de $1,8 \%$. Outros elementos presentes na lama estão abaixo de $0,1 \%$, tais como: alumínio, manganês, sódio, potássio, fósforo, enxofre e titânio. A concentração média de sódio na lama fina é de $0,12 \%$, enquanto que a de potássio é de $0,14 \%$.

\subsection{Concreto}

O traço para a produção do concreto apresentou boa trabalhabilidade na mistura com adição de $5 \%$ de lama fina de aciaria. Os ensaios de resistência à compressão axial ocorreram nas idades de 7 dias (para se verificar a resistência inicial da mistura), 14 dias (para acompanhar o desenvolvimento da resistência à compressão axial das amostras) e 28 dias (para as conclusões finais de resistência à compressão axial). A mistura apresentou uma tonalidade mais escura se comparada à mistura sem adição de lama fina de aciaria (Figura 7). Visualmente os corpos de prova de 5\% não apresentaram espaços vazios, e porosidade menor que a dos corpos de prova sem adição de lama fina de aciaria.

Os corpos de prova com adição de $5 \%$ de lama fina de aciaria adicionada ao traço apresentaram os melhores resultados nos ensaios de compressão axial, atingindo 29,3 MPa e 37,4 MPa nas idades de 14 e 28 dias respectivamente (Figura 8). Tais corpos apresentaram boa trabalhabilidade e homogeneidade dos componentes da mistura, não havendo desagregação das partículas, não apresentando ponto de aglomeração de nenhum dos componentes e tendo um ponto de acabamento superficial após a realização do arrasamento.

Os corpos de prova com adição de $10 \%$ de lama fina de aciaria apresentaram boa trabalhabilidade durante o período de moldagem, contudo perderam um pouco da homogeneidade dos componentes da mistura, apresentando aglomeração do cimento com a lama fina de aciaria. Em relação ao corpo de prova sem adição de lama fina de aciaria, o corpo de prova com adição de $10 \%$ apresentou um ganho de $8,42 \%$ na resistência à compressão axial no ensaio de 28 dias, porém, nos ensaios de 7 e 14 dias as resistências à compressão axial não atenderam aos mínimos aceitáveis para o concreto. Já nos corpos de prova com adição de $20 \%$, a

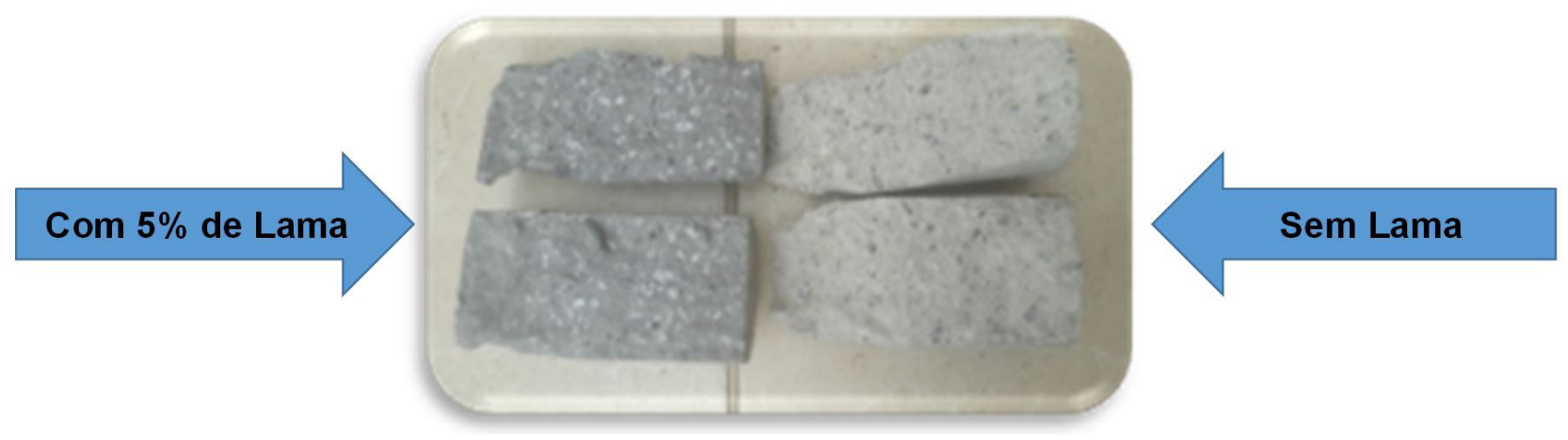

Figura 7. Comparação na tonalidade dos corpos de prova com 5\% de lama fina de aciaria e sem adição de lama fina de aciaria. 


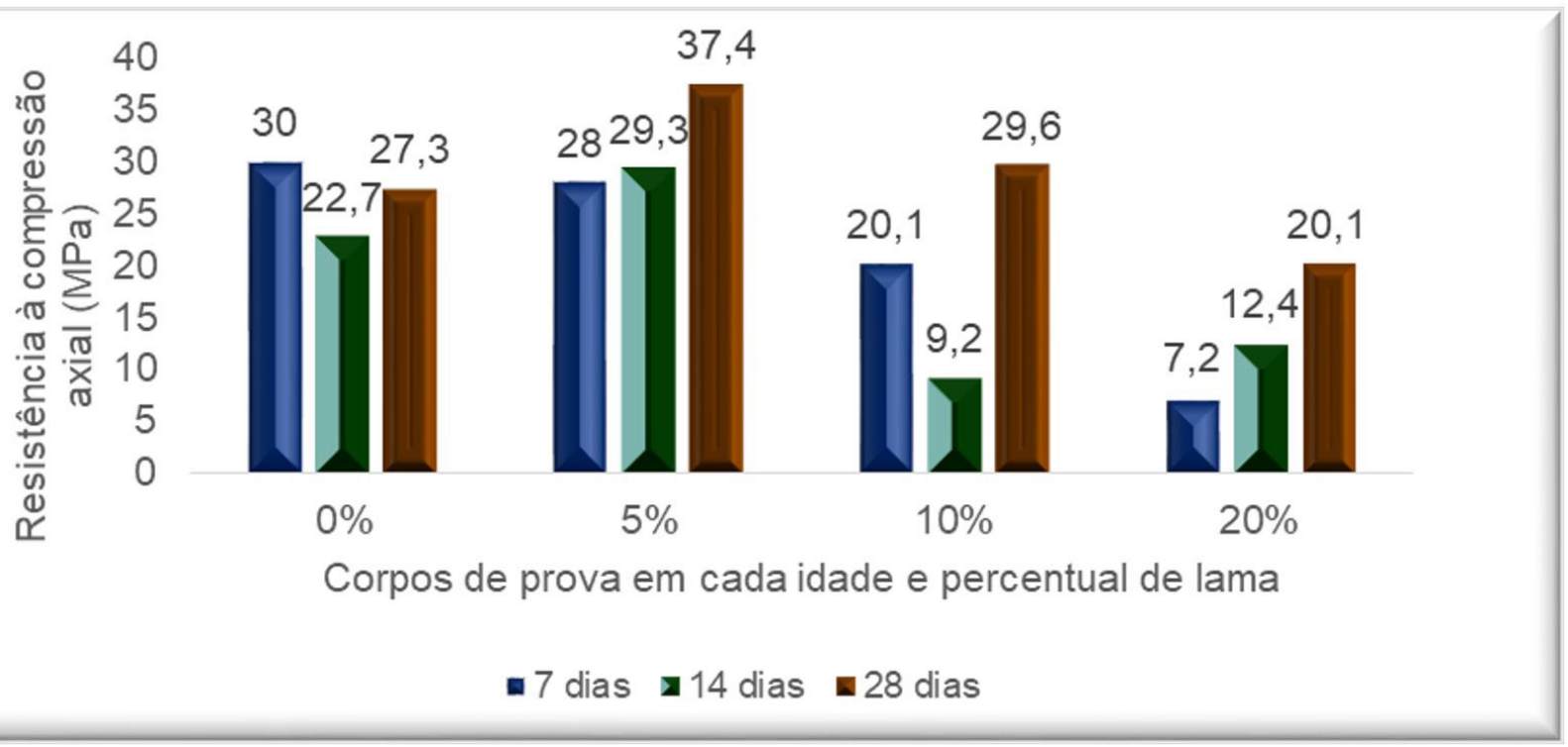

Figura 8. Resistência à compressão axial por percentual de adição de lama. Ensaios em triplicata.

trabalhabilidade ficou comprometida, uma vez que a mistura perdeu homogeneidade dos componentes e apresentou aglomeração dos componentes. Com isso, a adição de $20 \%$ de lama fina de aciaria à mistura não apresentou valores de resistência à compressão axial minimamente aceitáveis para a utilização do concreto.

\section{Conclusões}

O fato da lama fina de aciaria apresentar características granulométricas semelhantes às de um agregado miúdo mostrou-se relevante para a produção do concreto. A granulometria da fração fina da lama de aciaria mostra $85 \%$ de suas partículas menores que $0,038 \mathrm{~mm}(38 \mu \mathrm{m})$, sendo $70 \%$ menor que $0,001 \mathrm{~mm}(10 \mu \mathrm{m})$. O teor de ferro é aproximadamente $60 \%$ e o cálcio, $11 \%$. Além disso, a lama fina contém um teor de zinco considerável, $1,8 \%$ em média.
Os resultados obtidos nos ensaios de resistência à compressão axial, com a adição de 5\% da massa do agregado miúdo no período de 28 dias de cura, mostraram resistência superior à resistência do concreto convencional, no mesmo período. Já os resultados obtidos nos ensaios de resistência à compressão axial, com adição de $10 \%$ e $20 \%$ da massa do agregado miúdo em todos os períodos de cura, não satisfazem às normas. Portanto, em relação ao corpo de prova sem adição de lama fina de aciaria, o corpo de prova com adição de $5 \%$ da lama apresentou um ganho de $37,31 \%$ na resistência à compressão axial na idade de 28 dias. Os valores custeados pela siderúrgica com o resíduo são extremamente relevantes e, portanto, é salutar o apoio às pesquisas com a finalidade de buscar soluções e evitar possíveis danos à sociedade. Os resultados apontam grande potencial de aplicação, sendo indicada, portanto, a continuidade dos estudos, buscando identificar o melhor percentual entre $0 \%$ a $5 \%$ de aplicação do resíduo no concreto, assim como, a possibilidade de substituição ao agregado miúdo.

\section{Referências}

1 Instituto Brasileiro de Siderurgia. Siderurgia brasileira: princípios e políticas. São Paulo: IBS; 2007 [acesso em 5 nov. 2016]. Disponível em: https://www.ibs.com.br.

2 Benedetto JS, Ladeira ACQ. Tratamento e reciclagem de efluentes líquidos da indústria metal-metalúrgica. Relatório de projeto de pesquisa. Belo Horizonte: Centro de Desenvolvimento da Tecnologia Nuclear - CDTN/CNEN; 2007. 88 p.

3 Riani JC. Utilização de resinas de troca-iônica em efluentes de galvanoplastia [tese]. São Paulo: Universidade de São Paulo; 2008.

4 Cantarino MV. Estudo da remoção de zinco e de álcalis contidos em lamas de aciaria LD [dissertação]. Belo Horizonte: Universidade Federal de Minas Gerais; 2011.

5 John VM. Reciclagem de resíduos sólidos na construção Civil: contribuição à metodologia de pesquisa e desenvolvimento [tese]. São Paulo: Universidade de São Paulo; 2000. 
6 Levy SM. Reciclagem do entulho de construção civil, para utilização como agregado de argamassas e concretos [tese]. São Paulo: Universidade de São Paulo; 1997.

7 Pinto TP. Metodologia para a gestão diferenciada de resíduos sólidos da construção urbana [tese]. São Paulo: Universidade de São Paulo; 1999.

8 Santos EA, Borja EV. Investigação experimental de traços para blocos de concreto para alvenaria de vedação com adição de resíduos de pneus reciclados. Holos. 2007;1:54-64.

9 Martín MI, López FA, Torralba JM. Production of sponge iron powder by reduction of rolling mill scale. Ironmaking \& Steelmaking. 2012;39(3):155-162.

10 Pereira AJ, Avelar KES, Lima ALS, Friede RR, Miranda MG. Justiça ambiental e o problema dos resíduos industriais. Semioses. 2016;9(1):67-76.

11 Silva NG, Brehm FA, Mancio M, Moraes CAM. Reutilização e reciclagem de resíduos siderúrgico. In: Anais do $7^{\circ}$ Fórum Internacional de Resíduos Sólidos e Mudanças Climáticas; 2016 Junho 15-17; Porto Alegre. Porto Alegre: Instituto Venturi para Estudos Ambientais; 2016. p. 1-10.

12 Lobato NCC. Gerenciamento de resíduos sólidos da indústria siderúrgica [tese]. Belo Horizonte: Universidade Federal de Minas Gerais; 2014.

13 Oliveira EA. Cinética de digestão alcalina da franklinita presente na lama fina de aciaria LD [dissertação]. Belo Horizonte: Universidade Federal de Minas Gerais; 2014.

14 Singh AKP, Raju MT, Jha U. Recycling of Basic Oxygen Furnace (BOF) sludge in iron and steel works. International Journal of Environmental Technology and Management. 2011;14(1-4):19-32.

15 Roslan NH, Ismail M, Abdul-Majid Z, Ghoreishiamiri S, Muhammad B. Performance of steel slag and steel sludge in concrete. Construction \& Building Materials. 2016;104:16-24.

16 Muhmood L, Vitta S, Venkateswaran D. Cementitious and pozzolanic behavior of electric arc furnace steel slags. Cement and Concrete Research. 2009;39(2):102-109.

Recebido em: 9 Jul. 2019

Aceito em: 9 Mar. 2020 